\title{
coRibavirin-induced Anemia in Patients with Chronic Hepatitis C Virus Infection
}

\author{
CITTO IULIAN TAISESCU" ${ }^{1 *}$, ALIN DEMETRIAN", VIOREL BICIUSCA ${ }^{3}$, ANICA DRICU4, STEFAN ALEXANDRU ARTENE $^{4}$, \\ CATALINA $\mathrm{CIOC}^{4}$, OANA TAISESCU ${ }^{5}$ \\ 'University of Medicine and Pharmacy, Department of Physiology, 2 Petru Rares Str., 200349, Craiova, Romania \\ ZUniversity of Medicine and Pharmacy, Department of Thoracic Surgery, 2 Petru Rares Str., 200349, Craiova, Romania \\ 3University of Medicine and Pharmacy, Department of Semiology, 2 Petru Rares Str., 200349, Craiova, Romania \\ 4University of Medicine and Pharmacy, Department of Biochimistry, 2 Petru Rares Str., 200349, Craiova, Romania \\ EUniversity of Medicine and Pharmacy, Department of Anatomy, 2 Petru Rares Str., 200349, Craiova, Romania
}

\begin{abstract}
Anemia associated with ribavirin (RBV) and interferon therapy in patients with chronic viral hepatitis $C$ is a hemolytic, multifactorial adverse effect, in direct correlation with the RBV dose. Additionally, the anemic syndrome is worsened by the interferon-induced bone marrow suppression of erythroid precursors. The resulting anemia is associated with low production of erythropoietin, similar to anemia seen in HIV-infected patients or in those with cancer. Our study was performed on a group of 28 patients with viral hepatitis $C$ treated with 3 MU interferon alfa 3 times a week and RBV 1000-1200 mg/day for 12 months. A normochromic normocytic anemia was observed, requiring a reduction of the RBV dose to $600 \mathrm{mg} /$ day if the hemoglobin was below $10 \mathrm{~g} / \mathrm{dL}$ and interrupted if the hemoglobin level was below $8.5 \mathrm{~g} / \mathrm{dL}$. In this case, reversibility can occur within a time interval of 4-8 weeks after discontinuation of treatment.
\end{abstract}

Keywords : ribavirin, chronic viral hepatitis C, anemia

Cytopenia is one of the most common and severe side effects of antiviral therapy [1]. Also, HCV infection can induce hemolytic anemia, leucopenia and thrombocytopenia. It is a well known fact that HCV persists and actively replicates in lymphocytes, leading to extrahepatocytic dissemination of the virus, thus persisting in the salivary glands, kidneys and bone marrow; subsequently, these areas become secondary sources of viral reinfection and contribute to the inhibition of the body's immune response [2].

Both interferon (PEG-IFN) and RBV can cause important noticeable hematologic alterations which can trigger or even worsen a precarious hematologic status, compromising the patients adherence to therapy [3]. Patients with chronic viral hepatitis C treated with IFN / PEG-IFN and RBV have multiple types of anemia: hemolytic anemia, nutritional defficiency anemia, simple chronic anemia or anemia resulting from bleeding, thus defining the concept of mixed anemia [4]. However, RBV is responsible for producing the strongest effect, in comparison to interferon-mediated bone marrow inhibition. RBV causes dose-dependent haemolytic anemia which is reversible after 4-8 weeks of discontinuous administration of the drug [5]. Hemolytic anemia is the major complication of RBV treatment resulting from the accumulation of RBV triphosphate in the red blood cells, which interferes with cellular functions [6-8].

RBV causes varying degrees of hemolysis in most patients, although dose reduction is only required in 7 to $9 \%$ of patients undergoing standard antiviral therapy. Therefore, a recorded medical history of hemolytic anemia, with $\mathrm{Hgb}<11 \mathrm{~g} / \mathrm{dL}$ and $\mathrm{Ht}<33 \%$, are considered exclusion criteria for RBV administration [9].

\section{Experimental part}

Material and method

The study was performed on a group of 28 patients with viral hepatitis C admitted to the Second Medical Clinic of the Emergency County Hospital of Craiova who received 3 MU of interferon alfa 3 times a week and RBV $1000-1200$ $\mathrm{mg} /$ day for 12 months.

Patients were selected for treatment initiation in accordance with the following criteria: anti-HCV antibodies were present; detectable levels of viremia; histological lesions of chronic moderate or severe chronic hepatitis (HAl index> 6, Ishak score); ages 18-70; without any associated serious conditions (heart failure, preexisting psychiatric conditions, epilepsy, hemoglobinopathy, anemia, haemophilia, difficult to manage type I diabetes, autoimmune diseases); normal and slightly altered hematological and biochemical values: $\mathrm{Hb}>13 \mathrm{~g} \%$ for men and $\mathrm{Hb}>12 \mathrm{~g} \%$ for women; leukocyte count $>4000 / \mathrm{mmc}$; granulocyte count $>1500 / \mathrm{mmc}$; platelet count $>100,000$ / $\mathrm{mmc}$; creatinine $<1.2 \mathrm{mg} \%$; bilirubin $<2.5 \mathrm{mg} \%$; albumin $>3 \mathrm{~g} \%$; patients who were tested negative for pregnancy or patients who had the possibility of effective contraception during treatment.

Considering the absolute contraindications of antiviral medication, patients with the following illnesses were excluded from the beginning of our study: clinical signs of chronic decompensated liver disease (edema, haemorrhagic manifestations, portal encephalopathy, esophageal varices); autoimmune hepatitis; alcohol addiction or other toxic liver diseases; severe mental illness (depression); non-cooperating patients.

For this study, we selected and retained the blood panel during routine check-ups: full blood count (complete counts, morphological examination of the blood smear, reticulocyte count), myelogram (sternal puncture with morphological examination of the smears) and the red blood cells osmotic fragility test. Analyzers with 18 parameters were used: Celltac Nihon Kohden, Coulter AcT diff, Abacus J unior.

We used statistical methods for data analysis which allowed us to draw conclusions about the statistical significance and/or associations. We used the Excel and 
SPSS programs to perform statistical processing. The data obtained was correlated with additional data (anamnestic, serological and histological) from the patient records or the observation sheets. This information was entered into a Microsoft Office Excel database and processed statistically.

We performed a statistical study of haematological parameters in patients who showed a sustained virological response (SVR) at the end of treatment compared to nonSVR patients. The study was conducted with the approval of the Ethics Committee of the University of Medicine and Pharmacy of Craiova. A written consent was obtained from each patient included in the study.

We evaluated and compared the safety of the therapeutic agents included in the therapeutic protocols by performing the appropriate analysis sets and the subsequent statistical analysis the main haematological parameters involved in the antiviral treatment management.

These results were correlated with sustained virological response, which evaluates the effectiveness of the treatment.

\section{Results and discussions}

The patients in this group were equally represented by males and females (14:14), aged 23-69 years, with a mean age of $50.48 \pm 10.96$ years. Analyzing the distribution of the patients by age group, we noticed that the majority of patients were over 40 years old ( 15 patients, $53.5 \%$ ).

The proportion of men was higher in the $31-40$ years ( $B$ : $F=6: 4$ ) and the 61-70 years age group (6: 0), while women had a larger presence in the 41- 50 ( $\mathrm{B}: \mathrm{F}=3: 6$ ) and $51-60$ years (2: 8) age group.

\section{Hemoglobin}

$\mathrm{Hb}$ values, prior to initiation of therapy, were between 11.90 and $16.80 \mathrm{~g} / \mathrm{dL}$, with an average value of $14.82 \pm$ $1.21 \mathrm{~g} / \mathrm{dL}$ (fig. 1).

At the end of the 12 months of treatment, $\mathrm{Hb}$ values ranged between 9.80 and $14.20 \mathrm{~g} / \mathrm{dL}$, with an average of $11.19 \pm 1.49 \mathrm{~g} / \mathrm{dL}$ (table 1, fig.2).

Over $95 \%$ of patients experienced a decrease in hemoglobin levels by at least $\mathrm{Ig} / \mathrm{dL}$; while $6 \%$ of the men and $8 \%$ of the women experienced a $5 \mathrm{~g} / \mathrm{dL}$ or larger decrease in $\mathrm{Hb}$ levels, suggesting that women are significantly more susceptible to reducing RBV doses.

The maximum decrease in $\mathrm{Hb}$ values is noted progressively during treatment, with the highest decrease being recorded during the last month (table 3 ).

Patients with higher hemoglobin values before treatment initiation showed greater decreases in hemoglobin levels compared to those with lower baseline values (fig. 3).

A drop in $\mathrm{Hb}$ levels under $10 \mathrm{~g} / \mathrm{dL}$, which required an interferon and/or RBV dose reduction, occurred in 4 out of the 28 patients (14.28\%) of the group.

\section{Reticulocyte count}

The number of reticulocytes before treatment was between 2.6 and $18 \%$, with an average of $9.73 \pm 2.77 \%$. Three months after initiation of therapy, reticulocyte counts ranged from 2.4 to $17 \%$ with an average of $2.31 \pm 1.26$ $\%$. At the end of the treatment period, the number of reticulocytes was between 1.6 and $14.5 \%$, with an average value of $7.06 \%$ (table 4 , fig. 4).

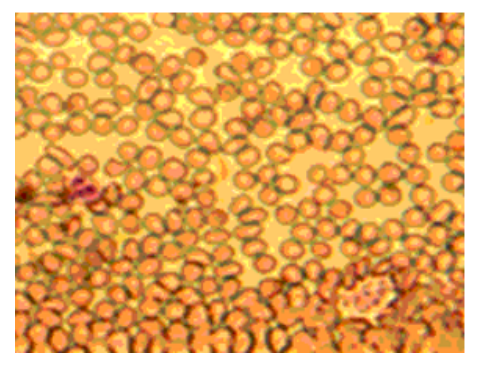

Fig. 1. A smear of peripheral blood from a patient prior to antiviral treatment. MGG coloration. 10x40

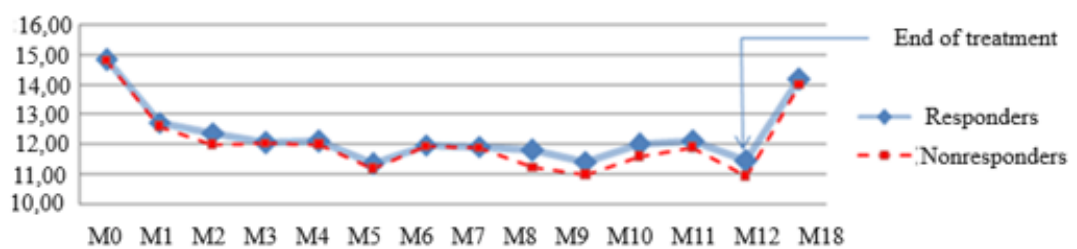

Fig. 2. The montly evolution of the mean $\mathrm{Hb}$ values

Table 1

THE MONTLY EVOLUTION OF THE MEAN Hb VALUES

\begin{tabular}{|l|l|l|l|l|l|l|l|l|}
\hline Hemoglobin & & M0 & M1 & M2 & M3 & M6 & M12 & M18 \\
\hline Responders & Number of patients & 13 & 13 & 10 & 13 & 10 & 13 & 13 \\
\cline { 3 - 9 } & Avg & 14.85 & 12.74 & 12.39 & 12.05 & 11.98 & 11.45 & 14.19 \\
\cline { 2 - 9 } & Std.Dev. & 1.28 & 1.18 & 1.56 & 1.81 & 1.68 & 1.65 & 1.26 \\
\hline Nonresponders & Number of patients & 15 & 15 & 10 & 15 & 10 & 15 & 15 \\
\cline { 2 - 9 } & Avg & 14.80 & 12.60 & 12.00 & 12.02 & 11.94 & 10.94 & 14.00 \\
\cline { 2 - 9 } & Std.Dev. & 1.14 & 1.06 & 1.79 & 2.10 & 1.34 & 1.34 & 1.21 \\
& & & & & & & & \\
\hline
\end{tabular}

Table 2

Hb LEVELS FOR MEN AND WOMEN

\begin{tabular}{|c|l|l|}
\hline \multirow{2}{*}{$\begin{array}{c}\text { Minimum } \\
\mathrm{g} / \mathrm{dl}\end{array}$} & \multicolumn{2}{|c|}{ Group } \\
\cline { 2 - 3 } & $\mathrm{n}(\%)$ & $\mathrm{n}(\%)$ \\
\hline$<10.0$ & $1(3.5)$ & $3(10.7)$ \\
\hline $10.0-11.0$ & $2(7.1)$ & $4(14.2)$ \\
\hline $11.0-12.0$ & $4(14.2)$ & $4(14.2)$ \\
\hline $12.0-13.0$ & $3(10.7)$ & $2(7.1)$ \\
\hline$>13.0$ & $4(14.2)$ & $1(3.5)$ \\
\hline
\end{tabular}


Table 3

PROGRESSIVE DECREASE IN HEMOGLOBIN LEVELS UP TO 12 MONTHS

\begin{tabular}{|c|c|c|c|c|c|c|c|c|c|c|c|c|}
\hline Hb & & M0 & & M1 & $\begin{array}{c}\text { Variation } \\
\text { from M0 } \\
\%\end{array}$ & $\mathrm{p}$ & M3 & $\begin{array}{c}\text { Variation } \\
\text { from M0 } \\
\%\end{array}$ & $\mathrm{p}$ & $\begin{array}{c}\text { M12 } \\
\text { Variation }\end{array}$ & $\begin{array}{c}\text { P } \\
\text { from M0 } \\
\%\end{array}$ & \\
\hline Responders & Avg & 14.85 & $100 \%$ & 12.74 & -14.21 & 0.008 & 12.05 & -18.86 & 0.003 & 11.45 & -22.90 & 0.001 \\
\cline { 2 - 12 } & $\begin{array}{c}\text { Std } \\
\text { Dev. }\end{array}$ & 1.28 & & 1.18 & & & 1.81 & & & 1.65 & & \\
\hline Nonresponders & Avg & 14.80 & $100 \%$ & 12.60 & -14.86 & 0.008 & 12.02 & -18.78 & 0.003 & 10.94 & -26.08 & 0.001 \\
\cline { 2 - 11 } & $\begin{array}{c}\text { Std } \\
\text { Dev. }\end{array}$ & 1.14 & & 1.06 & & & 2.10 & & & 1.34 & & \\
\hline
\end{tabular}



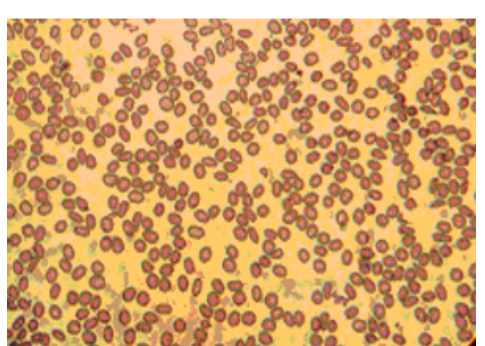

Fig.3. A smear of peripheral blood from a patient during the 6th month of antiviral treatment. MGG coloration. 10x40

\section{Mean corpuscular haemoglobin ( $\mathrm{MCH}$ )}

During treatment, $\mathrm{MCH}$ mean values increased steadily in all groups until the sixth month of treatment followed by a slightly downward curve; these results correlated with the observed macrocytosis on microscopically examined smears (table 5, fig. 5).

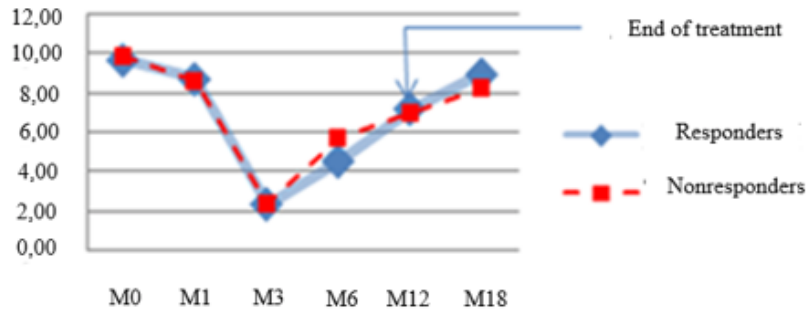

Fig. 4. The montly evolution of the mean reticulocyte values

\section{Morphological examination of the blood smear}

On smears prepared from capillary or venous blood, we found the same erythrocytic morphological changes in most patients, with a similar evolution, regardless of the type of treatment administered: anisocytosis, either with macrocytosis or with microcitosis; poicilocytosis (ovalocytes), microsferocytosis - in patients with RBVinduced hemolytic anemia (fig. 6).

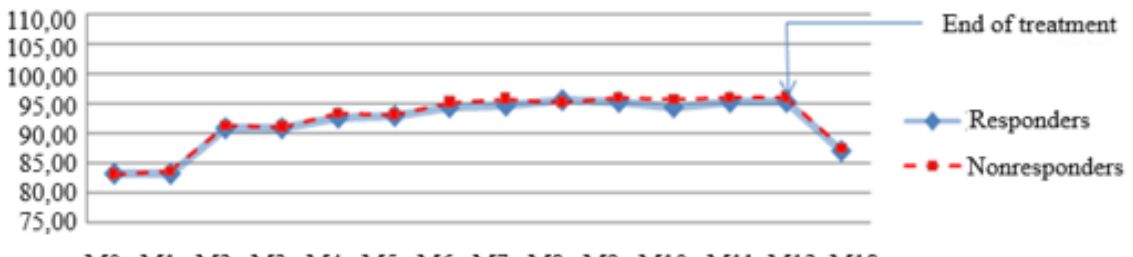

Fig 5. IFN+ RBV. Mothly evolution of mean $\mathrm{MCH}$ values 


\begin{tabular}{|c|c|c|c|c|c|c|c|c|}
\hline $\mathrm{MCH}$ & & $\mathrm{MO}$ & M1 & $\mathrm{M} 2$ & $\mathrm{MB}$ & M6 & $\mathrm{M} 12$ & M18 \\
\hline \multirow[t]{3}{*}{ Responders } & Number of patients & 13 & 13 & 10 & 13 & 10 & 13 & 13 \\
\hline & Average & 83.30 & 83.35 & 91.04 & 91.04 & 94.45 & 95.31 & 86.95 \\
\hline & Std.Dev. & 12.17 & 12.21 & 12.88 & 12.65 & 13.61 & 13.28 & 12.46 \\
\hline \multirow[t]{3}{*}{ Nonresponders } & Number of patients & 15 & 15 & 10 & 15 & 10 & 15 & 15 \\
\hline & Average & 83.11 & 83.58 & 91.20 & 91.11 & 95.21 & 96.08 & 87.40 \\
\hline & Std.Dev. & 12.08 & 12.62 & 12.77 & 13.04 & 13.58 & 13.16 & 12.22 \\
\hline
\end{tabular}

Table 5

MOTHLY EVOLUTION OF MEAN MCH VALUES

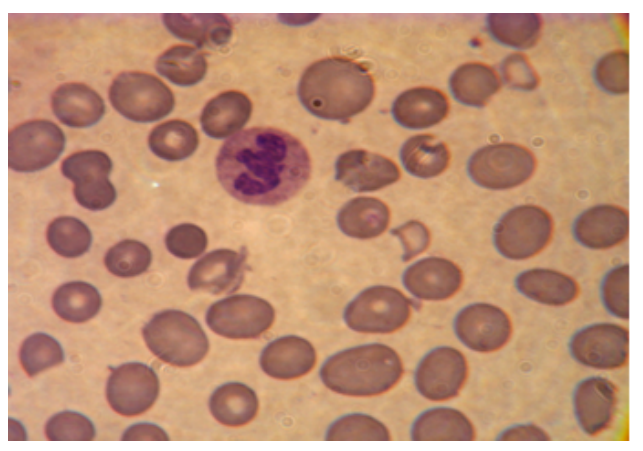

Fig. 6. Morphological changes of red blood cells during M6. Thrombocytopenia. Leukopenia.

\section{Morphological examination of the bone marrow}

$90 \%$ of patients accepted the sternal puncture performed for haematological pretreatment evaluation. Subsequently, a second sternal puncture was performed randomly in a small number of patients, either in M3 or M6 or M12; we found different degrees of cellular hypoplasia, with increased fibrous component in $40 \%$ of patients, and increased fat content in elderly patients [10].

RBV causes different degrees of hemolysis in almost all patients. Therefore, patients with pre-existing haemolysis or anemia $(\mathrm{Hb}<10 \mathrm{~g} / \mathrm{dL}$ ) should not be treated with RBV [11]. Similarly, patients with significant coronary or cerebrovascular disease should not be treated with RBV due to the fact that treatment-induced anemia can induce ischaemia. Acute myocardial infarction and fatal stroke have been reported in patients receiving PEG-IFN and RBV [12].

RBV is eliminated from the body by the kidneys. Patients with kidney disease can experience severe, life-threatening haemolysis. Patients with creatinine levels higher than 2 $\mathrm{mg} / \mathrm{dL}$ (which qualifies as renal dysfunction) should not be treated with RBV.

Over $95 \%$ of patients presented decreased $\mathrm{Hb}$ levels, by at least $1 \mathrm{~g} / \mathrm{dL} ; 6 \%$ men and $8 \%$ women presented a drop in $\mathrm{Hb}$ levels by at least $5 \mathrm{~g} / \mathrm{dL}$, suggesting that women are significantly more susceptible to reductions in RBV doses as recommended in current guidelines for the management of treatment-induced anemia.

Hemoglobin decreased significantly during treatment, with a maximum decrease of $26.08 \%$ correlated with the lack of therapeutic response.

After one month of treatment, hemoglobin decreases by $14.51 \%$ in patients receiving combined therapy, regardless of the form of interferon.

In the following months, hemoglobin remained at a constant low level, with a maximum decrease of $24.49 \%$ during M12. Until the sixth month, $\mathrm{Hb}$ values below $11 \mathrm{~g} /$ $\mathrm{dL}$ occurred in $21 \%$ of the patients in the group, and the decrease below $10 \mathrm{~g} / \mathrm{dL}$ was noted in $6 \%$ of patients.

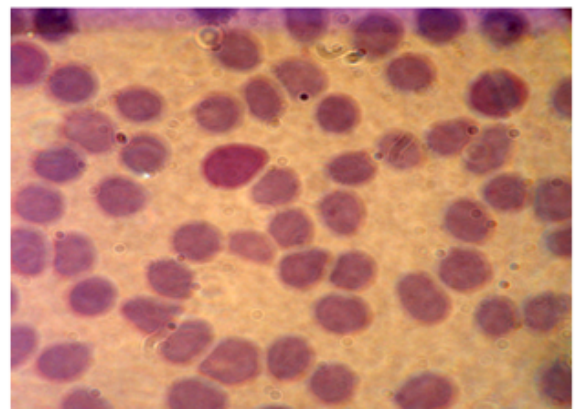

Fig. 7. A smear of peripheral blood from a patient during the 6th month of antiviral treatment (detail). MGG coloration. 10x100

$\mathrm{Hb}$ levels below $10 \mathrm{~g} / \mathrm{dL}$, which required dose reduction of PEG-IFN and / or RBV, occurred in 4 patients out of the 28 patients (14.28\%) in the group. RBV dose reduction was required in $21 \%$ of patients in the group.

Baseline values of $\mathrm{Hb}$ are reattained within 4 to 8 weeks after discontinuation. Reticulocytosis follows the same timeline, but in reverse.

Upon completion of treatment, $\mathrm{Hb}$ values return to normal at varying intervals, but values at the end of the monitoring period are below pretreatment values. Patients with higher $\mathrm{Hb}$ values before the treatment showed greater decreases in $\mathrm{Hb}$ values in comparison to those with lower baseline $\mathrm{Hb}$. The maximum decrease in $\mathrm{Hb}$ values is noted progressively during treatment, with the highest decrease in the last month.

Reticulocytosis occurs within the first 4 weeks of treatment. This complication is directly related to the pharmacological properties of the molecule and, in particular, its accumulation in erythrocytes. The occurrence of haemolytic anemia is very common.

The aspect of the bone marrow returned to normal 3 months after treatment in the majority of patients who accepted sternular puncture, with the exception of 2 female patients, 60 years of age, which presented a cellular hypoplasic appearance and predominance of fibrous and fatty components and in which the peripheral blood cell count remained at the lower limits of normal and at the end of the surveillance period.

It should also taken into account that lowering the dose of RBV affects the survival rates, so early steps to correct anemia are required to maintain the recommended doses. In addition to RBV induced anemia, IFN inhibits bone 
marrow hematopoietic activity, resulting in a lack of compensatory reticulocytosis with a negative impact on the already present anemia [5].

In patients with chronic hepatitis, and especially during antiviral treatment, even in the absence of anemia, changes in erythrocyte morphology are observed in the examination of blood smears such as changes in the shape and / or volume of the red blood cells $[13,14]$. The erythrocyte morphology thus provides information on viral activity, altering in concordance with the progression of hepatic injuries and also with bone marrow infection. Microcytosis accompanying pancytopaenia is the result of ineffective hematopoiesis in $25 \%$ of the cases, while $75 \%$ of cases occur because of medullary hypoplasia[15]. Additionally, hypersplenism contributes to the haematological changes [1]. All of these changes are the result of HCV affinity for hematopoietic cells, because of the underlying chronic liver disease and antiviral medication. In many instances, macrocytosis is accompanied by higher bilirubin levels and more frequently, thrombocytopenia in over $50 \%$ of patients with chronic hepatitis and over $60 \%$ of patients with cirrhosis [11]. Some authors $[3,16]$ consider macrocytosis as a poor prognostic factor for the progression of chronic liver disease towards cirrhosis.

Anemia affects the tolerability and efficacy of HCV treatment being associated with asthenia and decreased quality of life, as shown by other studies $[6,17]$. It would be preferable for clinicians to consider both relative and absolute decreases in hemoglobin levels as part of adverse reactions such as asthenia, dyspnoea, etc [18].

\section{Conclusions}

The main adverse effect of RBV was a regenerativetype normocytic normochromic anemia. The levels of reticulocytosis encountered in our study are directly related to the pharmacological properties of the RBV molecule and, in particular, its accumulation in erythrocytes. The RBV dose should be reduced to $600 \mathrm{mg} /$ day if the hemoglobin is below $10 \mathrm{~g} / \mathrm{dL}$ and discontinued when the hemoglobin levels fall below $8.5 \mathrm{~g} / \mathrm{dL}$. Blood panels performed at 2, 4, 6, 8 weeks of treatment followed by 4 week intervals have the effect of detecting significant decreases in hemoglobin and adjusting the doses of antiviral agents for an optimum treatment regimen. Baseline values are reobtained within 4 to 8 weeks of treatment discontinuation.

\section{References}

1.CHAYAMA K, HAYESCN, ABE H etal. IL28B but not ITPA polymorphism is predictive of response to pegylated interferon, ribavirin, and telaprevir triple therapy in patients with genotype 1 hepatitis $\mathrm{C}$. J Infect Dis 2011; 204: 84-93.

2.ESKESEN AN, MELUM E, MOGHADDAM A et al. Genetic variants at the ITPA locus protect against ribavirin-induced hemolytic anemia and dose reduction in an HCV G2/G3 cohort. Eur J Gastroenterol Hepatol 2012; 24: 890-896.
3.PONZIANI FR, MANGIOLA F, BINDA C et al. Future of liver disease in the era of direct acting antivirals for the treatment of hepatitis $C$. World J Hepatol 2017; 9: 352-367.

4.COPPOLA N, DE PASCALIS S, MESSINA $V$ et al. ITPase activity modulates the severity of anaemia in HCV-related cirrhosis treated with ribavirin-containing interferon-free regimens. Antivir Ther 2017; 22: 551-558.

5.FERENCI P, BERNSTEIN D, LALEZARI J et al. ABT-450/r-ombitasvir and dasabuvir with or without ribavirin for HCV. N Engl J Med 2014; 370: 1983-1992.

6.HITOMI Y, CIRULLI ET, FELLAY J et al. Inosine triphosphate protects against ribavirin-induced adenosine triphosphate loss by adenylosuccinate synthase function. Gastroenterology 2011; 140: 1314 1321.

7.OLARU M, MALAESCU D, DEMETRIAN A et al. A combined imagistic and morphological approach of lung tumors: study on 64 cases. Rom J Morphol Embryol 2013; 54: 1067-1074.

8.ALBULESCU DM, IONOVICI N, MOLDOVAN HR et al. Muscle metastases from cervical carcinoma - case report. Rom J Morphol Embryol 2017; 58: 545-551.

9.TAISESCU CI, ILIESCU G, TAISESCU 0 et al. Haematological adverse effects of interferon and ribavirin treatment in patients with chronic $C$ virus hepatitis. FARMACIA 2015; 63: 465-469.

10. CIUCA, I.M., POP, L.L., ROGOBETE, A.F., ONET, D.I., GUTAALMAJAN, B., POPA, Z.H.F., Genetic Expression in Cystic Fibrosis Related Bone Disease. An Observational, Transversal, Cross-sectional Study. Chim. Lab, 2016, 62 (9):1725-1730, doi: 10.7754 / Chim.Lab., 2016.160141

11.GHANY MG, NELSON DR, STRADER DB et al. An update on treatment of genotype 1 chronic hepatitis $C$ virus infection: 2011 practice guideline by the American Association for the Study of Liver Diseases. Hepatology 2011; 54: 1433-1444.

12.FRIED MW, SHIFFMAN ML, REDDY KR et al. Peginterferon alfa-2a plus ribavirin for chronic hepatitis $C$ virus infection. New England Journal of Medicine 2002; 347: 975-982.

13.MAAN R, VAN DER MEER AJ, BROUWER WP et al. ITPA Polymorphisms Are Associated with Hematological Side Effects during Antiviral Therapy for Chronic HCV Infection. PLoS One 2015; 10: e0139317.

14.PAGE T, CONNOR JD. The metabolism of ribavirin in erythrocytes and nucleated cells. Int J Biochem 1990; 22: 379-383.

15.FELLAY J, THOMPSON AJ, GE D et al. ITPA gene variants protect against anaemia in patients treated for chronic hepatitis $C$. Nature 2010; 464: 405-408.

16.NAGGIE S, RALLON NI, BENITO J M et al. Variants in the ITPA gene protect against ribavirin-induced hemolytic anemia in HIV/HCVcoinfected patients with all HCV genotypes. J Infect Dis 2012; 205: 376383.

17.ESPOSITO I, BENITEZ-GUTIERREZ L, TREVINO A et al. Impact of ITPA gene polymorphisms on the risk of ribavirin-induced haemolytic anaemia using interferon-free antivirals for chronic hepatitis $C$. Antivir Ther 2017; 22: 571-575.

18.CHIVU OR, MEDERLE O, SEMENESCU A et al. The Determination of the Noise Pollution in a Production Hall and the Diseases Produced by It. Rev. Chim. (Bucharest),69, no. no. 4, 2018, p. 875-880

$\overline{\text { Manuscript received: } 21.09 .2018}$ 